\title{
Analisis Dinding Geser pada Desain Bangunan Gedung Bertingkat yang Tidak Beraturan
}

\author{
${\text { Trias Widorini }{ }^{1} \text {, Ngudi Hari Crista }{ }^{2} \text {, Bambang Purnijanto }}^{3}$ \\ 1,2,3, Universitas Semarang, Indonesia \\ *email :triaswidorini@usm.ac.id
}

\begin{abstract}
Asymmetrical or irregular building construction must be designed to withstand lateral loads such as wind and earthquake. Asymmetrical building shape results in non-uniform mass distribution. The effect of shear wall placement and how effective the use of shear walls is in irregular multilevel buildings is due to earthquake lateral forces.

This study aims to compare horizontal deviations that occur due to earthquake loads in irregular buildings with variations in the location of the shear wall. The study compared three structural models with different shear walls. Model 1 is a structure designed without a shear wall, model 2 uses a shear wall at the edge, model 3 uses a shear wall in the elevator. Layout building have asymmetrical structure plans. This causes the horizontal deviation that occurs has a different value for each direction of the earthquake that occurred, namely the $X$ direction earthquake and $Y$ direction earthquake.

Based on the results of modeling analysis with variations in the layout of the shear wall, it can be concluded that the shear wall contributes greatly to the structure of multilevel buildings in resisting lateral forces such as earthquake loads and the location of shear walls in high rise buildings influences in terms of horizontal deviation values.
\end{abstract}

Keywords: shear wall; irregularity; displacements

\begin{abstract}
ABSTRAK
Pembangunan gedung bertingkat yang tidak simetris atau tidak beraturan harus dirancang menahan beban lateral seperti beban angin dan gempa. Selain itu, bentuk bangunan yang tidak simetris mengakibatkan distribusi massa yang tidak seragam. Pengaruh penempatan dinding geser dan berapa efektif penggunaan dinding geser pada gedung bertingkat tidak beraturan tehadap gaya lateral gempa.

Tujuan dari penelitian ini adalah untuk membandingkan simpangan horisontal yang terjadi akibat beban gempa pada gedung yang tidak beraturan dengan variasi letak dinding geser. Penelitian membandingkan tiga model struktur yang letak dinding gesernya berbeda. Model 1 adalah struktur yang didesain tanpa dinding geser, model 2 menggunakan dinding geser di tepi, model 3 Menggunakan dinding geser di lift. Denah bangunan memiliki denah struktur yang tidak simetris. Hal tersebut menyebabkan simpangan horisontal yang terjadi memiliki nilai yang berbeda untuk setiap arah gempa yang terjadi, yaitu gempa arah $\mathrm{X}$ dan gempa arah $\mathrm{Y}$.

Berdasarkan hasil analisa pemodelan dengan variasi tata letak dinding geser atau shear wall, dapat ditarik kesimpulan bahwa dinding geser memberikan kontribusi besar terhadap struktur bangunan bertingkat dalam menahan gaya lateral seperti beban gempa dan letak dinding geser pada bangunan bertingkat berpengaruh dalam hal nilai simpangan horisontal.
\end{abstract}

Kata Kunci: dinding geser; tidak beraturan; simpangan horizontal 


\section{PENDAHULUAN}

Dewasa ini makin banyak pembangunan gedung bertingkat, hal ini merupakan solusi untuk memanfaatkan lahan yang kurang luas untuk suatu fungsi tertentu seperti tempat tinggal, hotel, perkantoran dan lain sebagainya. Kebutuhan arsitek tidak hanya menuntut fungsi bangunan tetapi juga berkembangnya desain dan bentuk bangunan yang tidak simetris atau tidak beraturan.

Indonesia terletak pada pertemuan tiga lempeng sehingga Indonesia termasuk negara yang rawan terhadap gempa. Sehingga bangunan gedung bertingkat yang efisien dalam pemanfaatan lahan dan tidak simetris harus didesain juga mampu menahan beban gempa. Dinding geser merupakan struktur dinding yang terbuat dari beton bertulang yang dirancang untuk menahan gaya lateral akibat gempa.

Dinding geser (shear wall) didefinisikan sebagai komponen struktur yang relatif sangat kaku. Fungsi dinding geser berubah menjadi dinding penahan beban jika dinding geser menerima beban tegak lurus dinding geser. Bangunan beton bertulang yang tinggi sering didesain dengan dinding geser untuk menahan kombinasi gaya geser, momen dan gaya aksial yang timbul akibat gempa. Menurut Imran (2016), dengan adanya dinding geser yang kaku pada bangunan, sebagian besar beban gempa akan terserap oleh dinding geser tersebut. Wahyu (2017) menjelaskan penempatan dinding geser tengah mempunyai nilai story drift kecil dibandingkan dengan dinding geser yang terletak disudut.

Pada penelitian ini, denah dan letak dinding geser berbeda dengan penelitian sebelumnya, sehingga diharapkan dapat menambah menambah informasi tentang pengaruh dinding geser pada gedung bertingkat, menambah informasi tentang letak dinding geser terhadap kekuatan bangunan menahan gaya lateral gempa serta pengetahuan dalam mendesain dinding geser menggunakan program SAP 2000.

\section{METODE}

Penelitian ini menggunakan metode analitis. Tahapan-tahapan penelitian dapat dilihat pada bagan alir berikut ini :

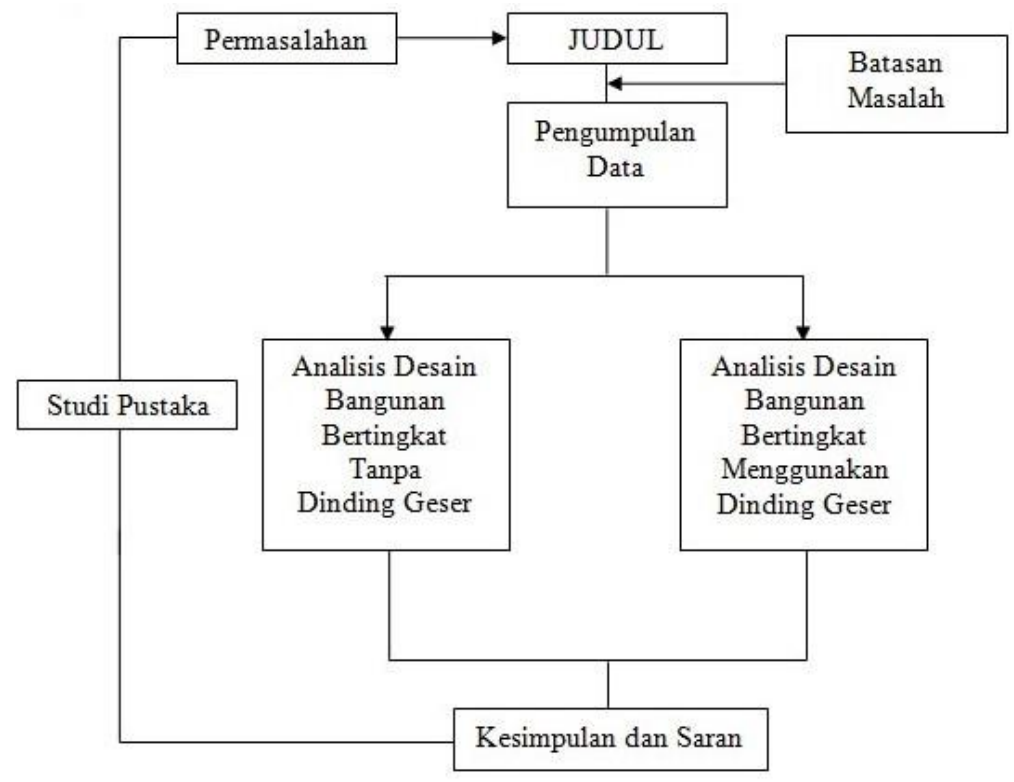

Gambar 1. Diagram Alir Penelitian

Dalam penelitian, langkah-langkah yang dilakukan adalah: 
a. Menentukan desain atau model bangunan bertingkat tidak beraturan.

b. Menentukan data-data pendukung dan beban-beban yang akan digunakan.

c. Membuat pemodelan struktur tiga dimensi dengan variasi letak dinding geser.

d. Melakukan analisis menggunakan software SAP 2000.

e. Analisis hasil perhitungan.

f. Dari hasil analisis dapat dibuat kesimpulan.

Berikut adalah data-data yang digunakan dalam mendesain model :

a. Fungsi gedung sebagai perkantoran

b. Beban Hidup (1t.1- 1t.5) $=250 \mathrm{~kg} / \mathrm{m}^{2}$

c. Beban Mati Tambahan (1t.1- 1t.5) $\quad=120 \mathrm{~kg} / \mathrm{m}^{2}$

d. Beban Hidup (1t.6) $\quad=100 \mathrm{~kg} / \mathrm{m}^{2}$

e. Beban Mati Tambahan (1t.6) $\quad=120 \mathrm{~kg} / \mathrm{m}^{2}$

f. Tinggi Tiap Lantai $=3,5 \mathrm{~m}$

g. Total Tingkat $=6$ lantai

h. Dimensi Kolom (1t.1- 1t.4) $=0,8 \mathrm{~m} \mathrm{x} \mathrm{0,8} \mathrm{m}$

i. Dimensi Kolom (1t.5-1t.6) $\quad=0,4 \mathrm{~m} \mathrm{x} \mathrm{0,4} \mathrm{m}$

j. Dimensi Balok Induk :

$$
\begin{array}{ll}
(B 1) & =0,8 \mathrm{~m} \times 0,4 \mathrm{~m} \\
\text { (B2) } & =0,7 \mathrm{~m} \times 0,35 \mathrm{~m}
\end{array}
$$
k. Dimensi Balok Anak (BA)
$=0,35 \mathrm{~m} \times 0,2 \mathrm{~m}$
1. Tebal Lantai (1t.1-1t.5)
$=0,12 \mathrm{~m}$
m. Tebal Lantai (1t.6)
$=0,10 \mathrm{~m}$
n. Mutu Beton Kolom
$=35 \mathrm{Mpa}$
o. Mutu Beton Balok dan Pelat
$=30 \mathrm{Mpa}$
p. Berat Jenis Beton
$=2400 \mathrm{~kg} / \mathrm{m}^{3}$

Data-data yang digunakan untuk analisis pembebanan gempa adalah sebagai berikut:

1. Pembebanan gempa dinamis menggunakan Response Spectrum

2. Pembebanan gempa statis menggunakan Equivalent Static Load (ELF)

3. Menggunakan data gempa di lokasi jalan Arteri Soekarno Hatta dengan hasil penyelidikan tanah diklasifikasikan dengan SE (tanah lunak).

Model ada 3 yaitu Model 1 tanpa dinding geser sedangkan Model 2 dan Model 3 Menggunakan dinding geser dengan variasi letak dinding geser yang berbeda.

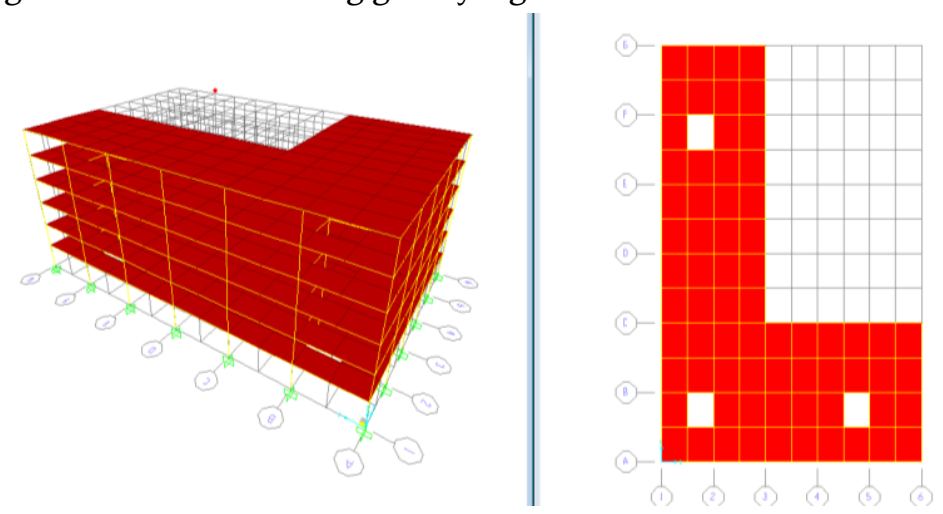

Gambar 2. Model 1 Tanpa Dinding Geser 


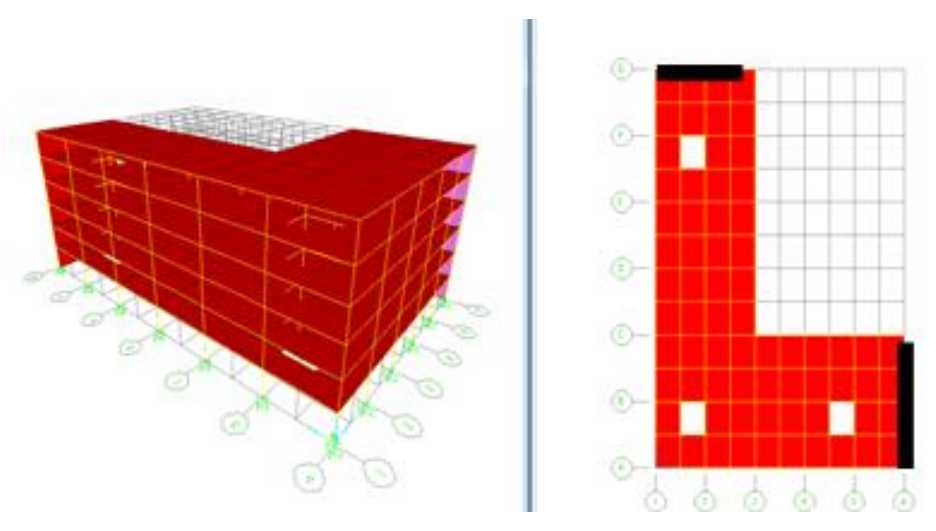

Gambar 3. Model 2 Dengan Dinding Geser Letak di Tepi
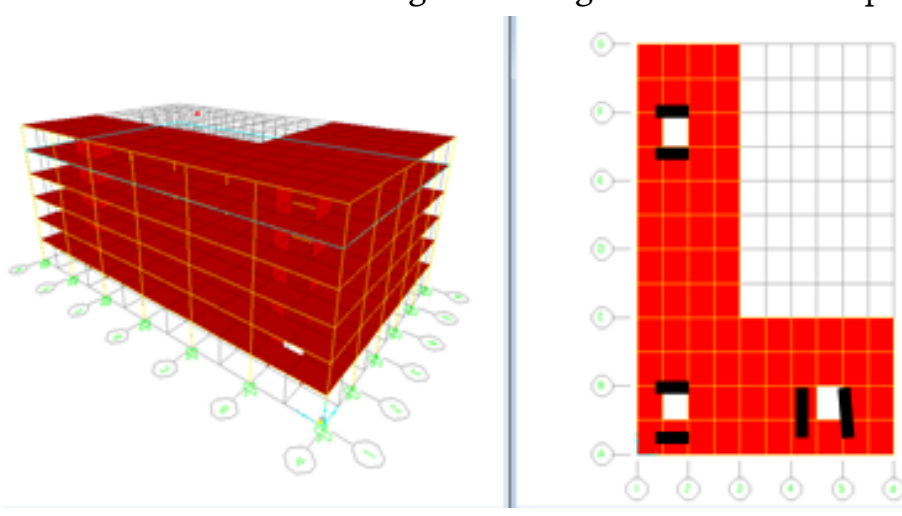

Gambar 4. Model 3 Dengan Dinding Geser Letak di Lift

\section{HASIL DAN PEMBAHASAN}

\section{Hasil Response Spectrum}

Berdasarkan lokasi bangunan adalah di jalan Arteri Soekarno Hatta didapat data yang diperlukan adalah sebagai berikut:

Percepatan batuan dasar pada periode pendek

Percepatan batuan dasar pada periode 1 detik

(Ss) $\quad=1.024 \mathrm{~g}$

Faktor amplifikasi

(S1) $=0.343 \mathrm{~g}$

$(\mathrm{Fa}) \quad=0.9$

$(\mathrm{Fv}) \quad=2,627$

Parameter spektrum respons

$$
\begin{array}{ll}
(\mathrm{Sms})=\text { Fa.Ss } & =0.922 \mathrm{~g} \\
(\mathrm{Sm} 1)=\text { Fv.S1 } & =0.902 \mathrm{~g}
\end{array}
$$

Parameter percepatan spektral desain

$$
\begin{array}{ll}
(\mathrm{SDS})=2 / 3 \mathrm{Sms} & =0.615 \mathrm{~g} \\
(\mathrm{SD} 1)=2 / 3 \mathrm{Sm} 1 & =0.601 \mathrm{~g} \\
\mathrm{~T} 0=0.2 \mathrm{SD} 1 / \mathrm{SDS} & =0.196 \text { detik } \\
\mathrm{Ts}=\mathrm{SD} 1 / \mathrm{SDS} & =0.978 \text { detik }
\end{array}
$$




\section{Kategori Desain Seismik}

Gedung berfungsi sebagai "Gedung perkantoran" sehingga masuk kategori resiko II dengan faktor keutamaan $(\mathrm{Ie})=1$. Penentuan Kategori Desain Seismik $(\mathrm{KDS})$ dengan nilai SDS $=0.615 \mathrm{~g}$ termasuk KDS D, sedangkan berdasarkan nilai SD1 $=0.601 \mathrm{~g}$ atermasuk KDS D. Sehingga dapat disimpulkan kategori desain seismik berdasarkan katagori resiko dengan nilai SDS dan SD1 termasuk dalam KDS D.

\section{Hasil Analisis Struktur}

Model 1 adalah struktur yang didesain tanpa dinding geser, Model 2 menggunakan dinding geser di tepi, Model 3 Mengunakan dinding geser di lift. Denah bangunan memiliki denah struktur yang tidak simetris. Hal tersebut menyebabkan simpangan horisontal yang terjadi memiliki nilai yang berbeda untuk setiap arah gempa yang terjadi, yaitu gempa arah X dan gempa arah Y.

Dari hasil analisis menggunakan SAP2000 diperoleh simpangan untuk beban dinamis arah $\mathrm{X}$ yang dapat dilihat pada Gambar berikut ini:

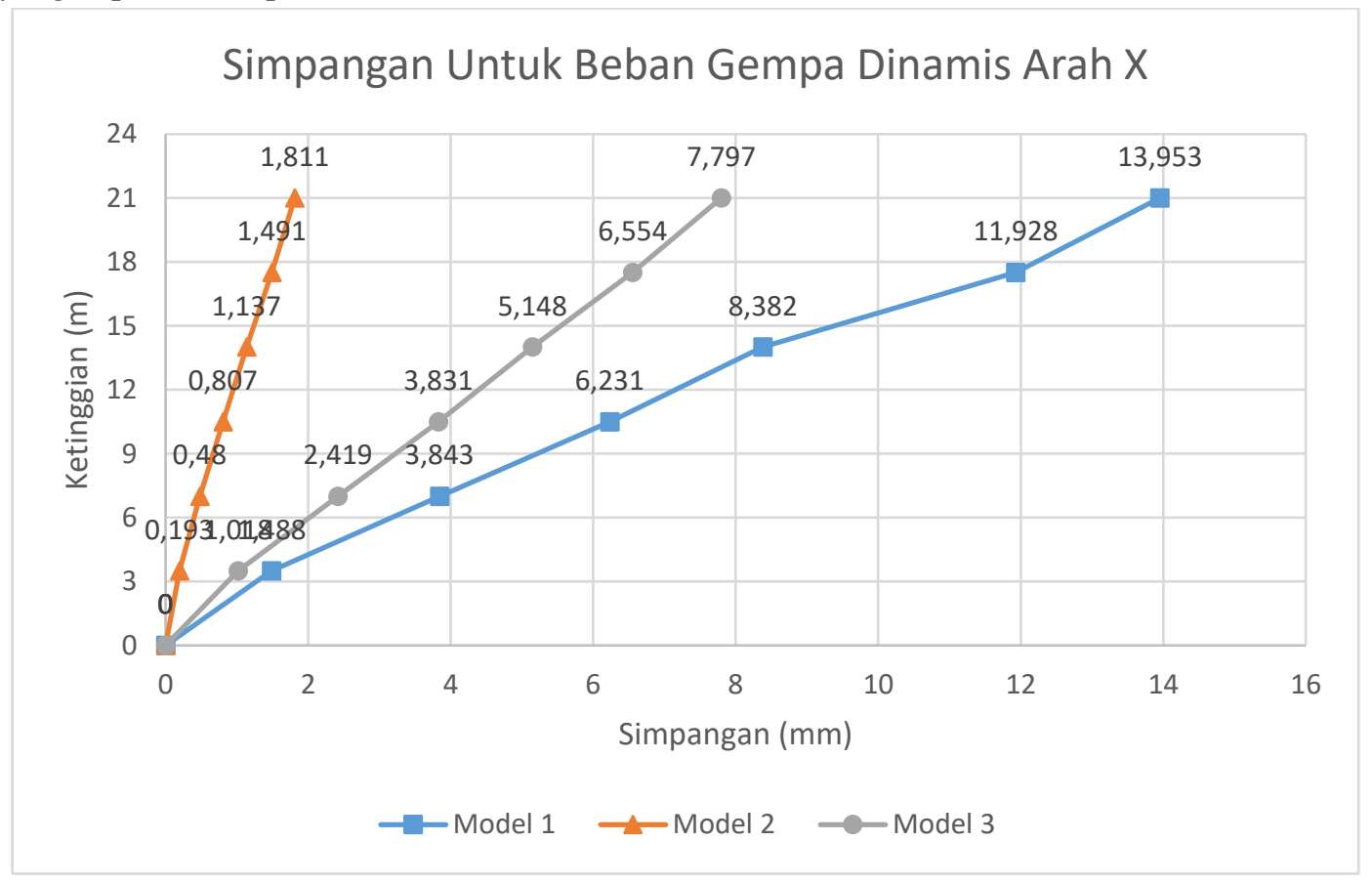

Gambar 5. Hasil Simpangan Untuk Beban gempa Dinamis Arah X

Berdasarkan Gambar 5, Model 2 menghasilkan nilai simpangan untuk beban gempa dinamis arah $\mathrm{X}$ yang paling kecil. Dengan letak dinding geser pada model 2 dibandingkan tanpa dinding geser dapat mengurangi simpangan hingga 87,02\% sedangkan denan model 3 dapat mengurangi simpangan hingga $44,12 \%$.

Dari hasil analisis menggunakan SAP2000 diperoleh simpangan untuk beban dinamis arah Y yang dapat dilihat pada Gambar 6. Berdasarkan Gambar 6, Model 2 juga menghasilkan nilai simpangan untuk beban gempa dinamis arah $\mathrm{Y}$ yang paling kecil. Pengurangan simpangan model 2 dibandingkan tanpa dinding geser dapat mengurangi simpangan hingga 39,88b\% sedangkan denan model 3 dapat mengurangi simpangan hingga 2,6\%. 


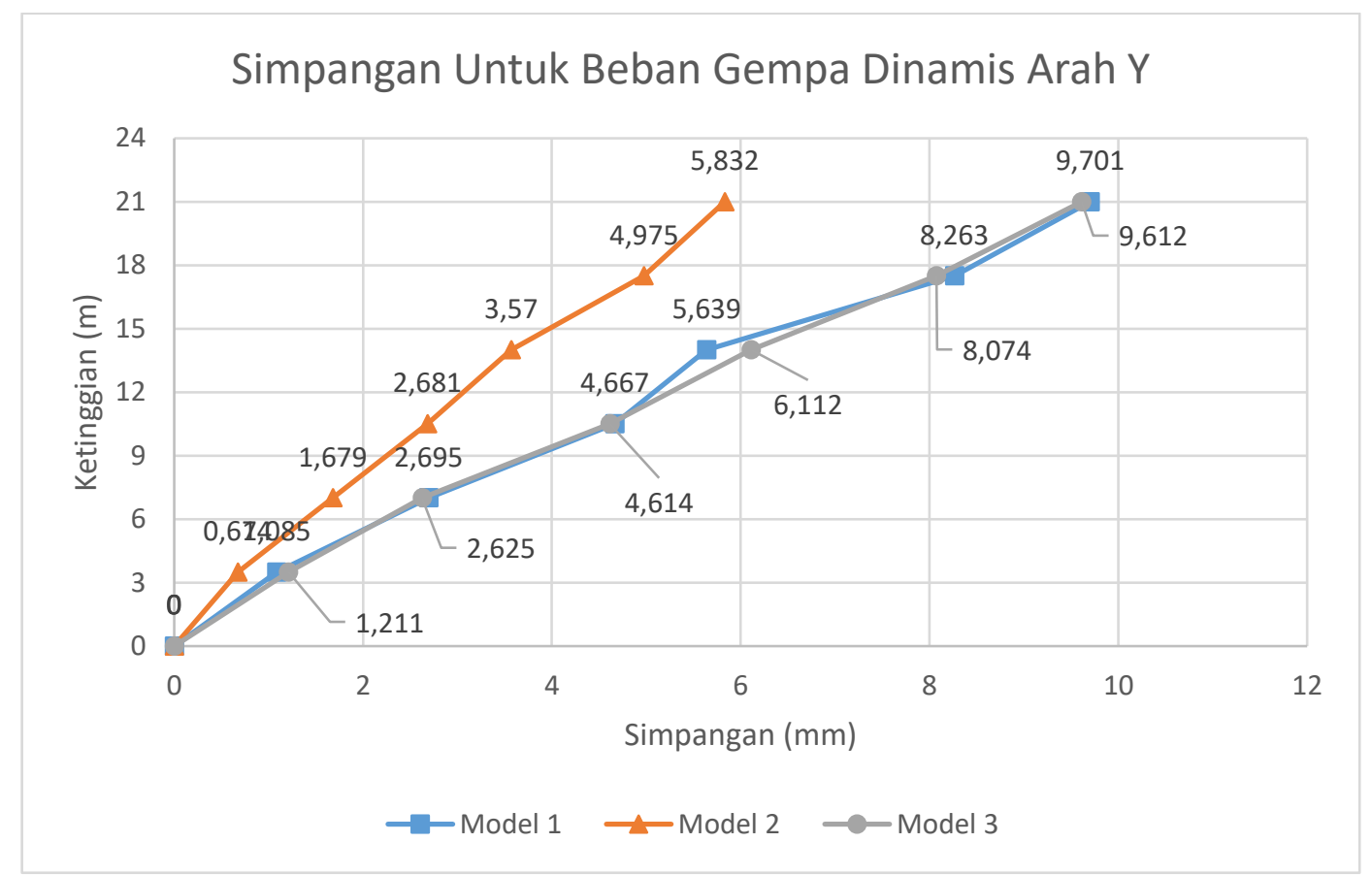

Gambar 6. Hasil Simpangan Untuk Beban gempa Dinamis Arah Y

Dari hasil analisis menggunakan SAP 2000 diperoleh simpangan untuk beban statis arah X yang dapat dilihat pada Gambar 7.

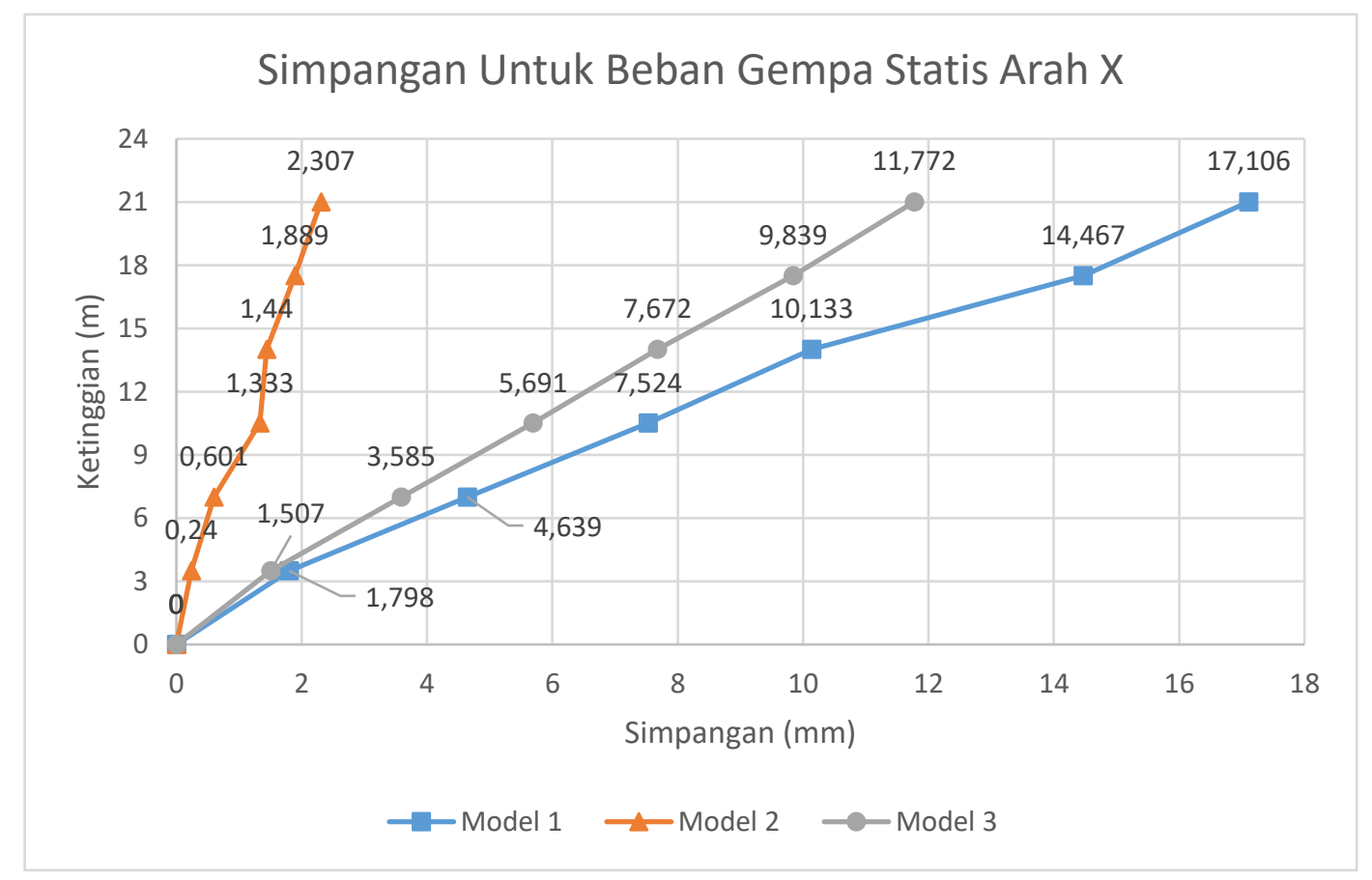

Gambar 7. Hasil Simpangan Untuk Beban gempa Statis Arah X

Berdasarkan Gambar 7, Model 2 menghasilkan nilai simpangan untuk beban gempa statis arah $\mathrm{X}$ yang paling kecil. Dengan letak dinding geser pada model 2 dibandingkan tanpa dinding geser 
dapat mengurangi simpangan hingga 87,04\% sedangkan denan model 3 dapat mengurangi simpangan hingga $31,18 \%$.

Dari hasil analisis menggunakan SAP2000 diperoleh simpangan untuk beban statis arah Y yang dapat dilihat pada Gambar 8 .

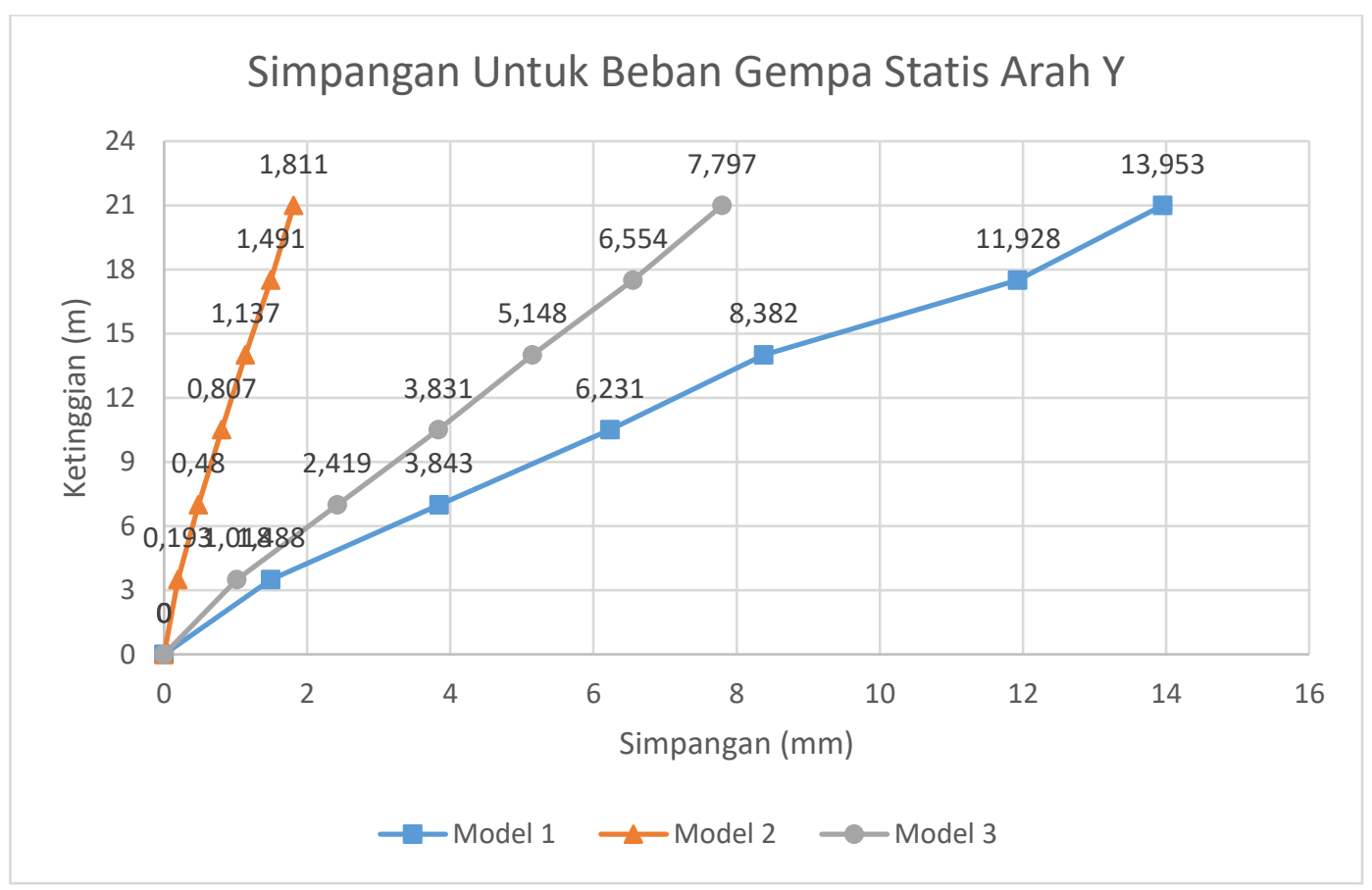

Gambar 8. Hasil Simpangan Untuk Beban gempa Statis Arah Y

Berdasarkan Gambar 8, Model 2 menghasilkan nilai simpangan untuk beban gempa statis arah $\mathrm{Y}$ yang paling kecil. Dengan letak dinding geser pada model 2 dibandingkan tanpa dinding geser dapat mengurangi simpangan hingga 87,51\% sedangkan denan model 3 dapat mengurangi simpangan hingga $45,05 \%$.

\section{SIMPULAN}

Berdasarkan hasil analisis pemodelan dengan variasi tata letak dinding geser atau shear wall, dapat ditarik kesimpulan bahwa dinding geser memberikan kontribusi besar terhadap struktur bangunan bertingkat dalam menahan gaya lateral seperti beban gempa. Letak dinding geser pada bangunan bertingkat berpengaruh dalam hal nilai simpangan horisontal.

\section{DAFTAR PUSTAKA}

Badan Standarisasi Nasional. 2012. "Tata Cara Perencanaan Ketahanan Gempa untuk Bangunan Gedung (SNI 03-1726-2012)". Jakarta.

Batu, Mikael Lumban, d1l. 2016. "Efisiensi Penggunaan Dinding Geser Untuk Mereduksi Efek Torsi Pada Bangunan Yang Tidak Beraturan”. Jurnal. Jurnal Sipil Statik Vol.4. Manado.

Fauzizah, Lilik, dkk. 2013. "Pengaruh Penempatan dan Posisi Dinding Geser Terhadap Simpangan Bangunan Beton Bertulang Bertingkat Banyak Akibat Gempa". Jurnal Jurnal Sipil Statik Vol 1

Imran, Iswandi, dkk. 2016. "Perencanaan Lanjut Struktur Beton Bertulang”. Bandung : ITB Press.

Majore, Bralen O, dll. 2015. "Studi Perbandingan Respon Dinamik Bangunan Bertingkat Banyak Dengan Variasi Tata Letak Dinding Geser". Jurnal. Jurnal Sipil Statik Vol.3. Manado 
Mc Cormac, J.C. 2003."Desain Beton Bertulang Jilid 2". Jakarta : Erlangga

Schueller, Wolfgang. 2001. "Struktur Bangunan Bertingkat Tinggi”. Bandung: Eresco.

Wahyu, Irfan, dkk. 2017. "Pengaruh Penambahan Dinding Geser pada Perencanaan Ulang Gedung Fave Hotel Surabaya”. Jurnal. Jurnal Rekayasa Teknik Sipil Vol 1 